\title{
MICROSTRUCTURE AND PROPERTIES OF MAO COMPOSITE COATINGS CONTAINING NANORUTILE $\mathrm{TiO}_{2}$ PARTICLES
}

\author{
ZHENWEI LI* and SHICHUN DI \\ School of Mechatronics Engineering, Harbin Institute of Technology \\ Harbin, Heilongjiang 150001, P. R. China \\ *lizhenwei20071212@163.com
}

Received 25 October 2016

Revised 14 February 2017

Accepted 22 February 2017

Published 2 March 2017

\begin{abstract}
Microarc oxidation (MAO) composite coatings containing rutile $\mathrm{TiO}_{2}$ were produced on 2024 aluminum alloy in an electrolyte with nanorutile $\mathrm{TiO}_{2}$ particles. The microstructure and properties of the composite coatings were analyzed by SEM, EDS, laser confocal microscope, XRD, Vickers hardness tester, scratch test and friction test, respectively. The results showed that the composite coatings consisted of $\gamma-\mathrm{Al}_{2} \mathrm{O}_{3}, \alpha-\mathrm{Al}_{2} \mathrm{O}_{3}$, mullite and rutile $\mathrm{TiO}_{2}$. With increasing concentration of rutile $\mathrm{TiO}_{2}$ particles in the electrolyte, the compactness of the composite coatings was improved significantly. The abrasion performance of the microarc oxidation composite coatings containing rutile $\mathrm{TiO}_{2}$ was better than that of $\mathrm{MAO}$ coatings without rutile $\mathrm{TiO}_{2}$.
\end{abstract}

Keywords: 2024 Aluminum alloy; microarc oxidation; nanorutile $\mathrm{TiO}_{2}$ particles; composite coatings; adhesion strength; abrasion performance.

\section{Introduction}

Light metals and their alloys are important structural materials and are extensively applied in aerospace and transportation systems. ${ }^{1,2}$ Aluminum alloys with excellent performance have received much attention. ${ }^{3}$ However, the applications of aluminum alloys are seriously restricted by their low surface hardness and high wear rate. ${ }^{4-7}$ To date, many aluminum alloy surface treatment methods have been developed and employed to improve the hardness and friction performance of aluminum alloy. However, most of these technologies require high temperature and are complex. In particular, they are not environmentally friendly. ${ }^{6,8-11}$ Microarc oxidation $(\mathrm{MAO})^{12-14}$ has emerged as a novel technique with broad application prospects. MAO can be used for the preparation of ceramic-like oxide coatings on some light metals based on anodic oxidation, thermochemistry, electrochemistry and plasma chemical mechanisms. The coatings prepared by MAO have high hardness, good adhesion to substrate, good abrasion resistance, etc. ${ }^{15-21}$

However, MAO coatings show high and unstable friction coefficient because of the ceramic properties, and MAO coatings contain many micropores, which are formed via continuous localized spark discharge events during the MAO process. These micropores in

\footnotetext{
${ }^{*}$ Corresponding author.
}

This is an Open Access article published by World Scientific Publishing Company. It is distributed under the terms of the Creative Commons Attribution 4.0 (CC-BY) License. Further distribution of this work is permitted, provided the original work is properly cited. 
Table 1. The electrolyte compositions.

\begin{tabular}{lccccc}
\hline Labels & $\begin{array}{c}\mathrm{Na}_{2} \mathrm{SiO}_{3} \\
(\mathrm{~g} / \mathrm{L})\end{array}$ & $\begin{array}{c}\mathrm{KOH} \\
(\mathrm{g} / \mathrm{L})\end{array}$ & $\begin{array}{c}\text { Rutile } \mathrm{TiO}_{2} \\
(\mathrm{~g} / \mathrm{L})\end{array}$ & $\begin{array}{c}\text { The pH of } \\
\text { electrolyte }\end{array}$ & $\begin{array}{c}\text { The conductivity of } \\
\text { electrolyte }(\mathrm{mS} / \mathrm{cm})\end{array}$ \\
\hline $\mathrm{a}$ & 11 & 1.5 & 0 & 12 & 7.21 \\
$\mathrm{~b}$ & 11 & 1.5 & 0.7 & 12 & 7.00 \\
$\mathrm{c}$ & 11 & 1.5 & 1.4 & 12 & 6.84 \\
$\mathrm{~d}$ & 11 & 1.5 & 2.1 & 12 & 6.93 \\
$\mathrm{e}$ & 11 & 1.5 & 2.8 & 12 & 6.89 \\
$\mathrm{f}$ & 11 & 1.5 & 3.5 & 12 & 6.97 \\
\hline
\end{tabular}

the MAO coatings, however, provide an opportunity to deposit nanoparticles with high hardness or low friction coefficient into the MAO coatings. Recently, the superior performance of MAO composite coatings formed by adding particle additives in the electrolyte has led to extensive attention. For example, using $\mathrm{ZrO}_{2}$ particles as additives, $\mathrm{Hu}$ prepared $\mathrm{Al}_{2} \mathrm{O}_{3} / \mathrm{ZrO}_{2}$ composite coatings via MAO. ${ }^{7}$ Self-lubricating $\mathrm{TiO}_{2} /$ graphite composite coatings and $\mathrm{TiO}_{2} / \mathrm{MoS}_{2}$ composite coatings were formed via $\mathrm{MAO}$ in an electrolyte containing graphite particles and in an electrolyte containing $\mathrm{MoS}_{2}$ particles, respectively. $\mathrm{TiO}_{2} / \mathrm{ZrO}_{2}$ composite coatings were produced via MAO in an electrolyte containing $\mathrm{ZrO}_{2}$ particles. ${ }^{22-30}$

Rutile $\mathrm{TiO}_{2}$ with high hardness, good oxidative stability and a high melting point is used as wearresistant materials. Moreover, nanorutile $\mathrm{TiO}_{2}$ particles can be used as a solid lubricant during wear testing. There is little work on using nanorutile $\mathrm{TiO}_{2}$ particles as additives in MAO composite coatings for improving the abrasion resistance of aluminum alloys. In this paper, 2024 aluminum alloy is processed via microarc oxidation in a silicate system electrolyte with different concentrations of nanorutile $\mathrm{TiO}_{2}$ particles. The microstructure and abrasion resistance of the $\mathrm{Al}_{2} \mathrm{O}_{3} / \mathrm{TiO}_{2}$ composite ceramic coatings are analyzed. The adhesion force between the coating and substrate is investigated.

\section{Experimental}

\subsection{Coatings preparation}

A 2024 aluminum alloy was used as the experimental material. The main alloy elements (mass fraction, wt.\%) of the 2024 aluminum alloy are $3.8-4.9 \% \mathrm{Cu}, 0.5 \% \mathrm{Si}$, $0.5 \% \mathrm{Fe}, 0.3-0.9 \% \mathrm{Mn}, 1.2-1.8 \% \mathrm{Mg}, 0.25 \% \mathrm{Zn}$, $0.10 \% \mathrm{Cr}$ and $0.15 \% \mathrm{Ti}$, and the remaining with $\mathrm{Al}$.
The sample size of the 2024 aluminum alloy was $30 \mathrm{~mm} \times 15 \mathrm{~mm} \times 2 \mathrm{~mm}$. The samples were polished using abrasive papers from $600 \sharp$ to $2000 \sharp$ and degreased by alcohol. An AC pulse microarc oxidation unit was used in this experiment. The electrolytic tank was used as the cathode and the sample was used as the anode. The silicate electrolyte was prepared in deionized water. The electrolyte compositions are given in Table 1 . The additives were rutile $\mathrm{TiO}_{2}$ nanoparticles, and the average size of the rutile $\mathrm{TiO}_{2}$ particles was approximately $35 \mathrm{~nm}$. The concentration of rutile $\mathrm{TiO}_{2}$ particles varied from $0 \mathrm{~g} / \mathrm{L}$ to $3.5 \mathrm{~g} / \mathrm{L}$ in the electrolyte. A bipolar constant current power supply was used in this experiment. The current density, MAO processing time, duty ratio and the frequency were $+27.8 \mathrm{~A} / \mathrm{dm}^{2} /-9.3 \mathrm{~A} / \mathrm{dm}^{2}, 30$ $\min , 43 \%$ and $100 \mathrm{~Hz}$, respectively. To improve the suspension performance of rutile $\mathrm{TiO}_{2}$ particles, the mixing pump was opened, and the electrolyte was stirred continuously during the MAO treatment. The cycle cooling system was opened to ensure that the electrolyte temperature was less than $40^{\circ} \mathrm{C}$.

\subsection{Testing and characterization}

The surface morphologies, cross-section morphologies and thickness of the MAO coatings and composite coatings formed in the electrolyte containing rutile $\mathrm{TiO}_{2}$ nanoparticles were analyzed by FEI Sirion scanning electron microscopy (SEM). The surface roughness of MAO coatings and composite coatings was measured using an OLS3000 laser confocal microscope, and the distribution of the main components of the MAO coatings and the composite coatings along the cross-section was analyzed by EDS. The phase structure of the MAO coatings and the composite coatings was analyzed via X'Pert PRO $\mathrm{X}$-ray diffraction (XRD). 
The adhesion force between coatings and substrate was investigated by a scratch test. A normal load through a diamond indenter was applied to the MAO coatings and composite coatings. The growth rate of the normal load was $35 \mathrm{~N} \cdot \min ^{-1}$ and the normal load was linearly increased from $0 \mathrm{~N}$ to $35 \mathrm{~N}$. The scratch length was $0.5 \mathrm{~cm}$. The critical load values $\left(L_{c}\right)$ were determined by supplementary data graphics containing acoustic emission, friction force and friction coefficient.

The hardness and abrasion resistance of the microarc oxidation coatings and the microarc oxidation composite coatings were analyzed using a Vickers hardness tester and CETR-UMT-2 ball-on-disk wear tester, respectively. WC balls with a surface roughness lower than $0.05 \mu \mathrm{m}$ and a diameter of $5 \mathrm{~mm}$ were chosen as the counterface materials. In the process of the wear tests, the applied load was $5 \mathrm{~N}$. The rotating diameter and rotating sliding speed of the wear tester were $6 \mathrm{~mm}$ and $100 \mathrm{r} / \mathrm{min}$, respectively. The test time of each sample measured on the wear tester was $40 \mathrm{~min}$. The volumes of wear tracks for the microarc oxidation coatings and microarc oxidation composite coatings were measured by an OLS3000 laser confocal microscope. The wear rates of the microarc oxidation coatings and the microarc oxidation composite coatings were determined by the volume of the wear tracks, applied load and sliding distance. The computation formula of the wear rate is as follows ${ }^{22}$ :

$$
Q=\frac{V}{F L} .
$$

In the above equation, $Q$ is the wear rate, $V$ is the wear volume $\left(\mathrm{mm}^{3}\right), F$ is the applied load $(\mathrm{N})$ and $L$ is the sliding distance $(\mathrm{m})$.

\section{Results and Discussion}

\subsection{Coating microstructure}

Figure 1 shows the variation curves of voltage. The voltage increased due to the growth of MAO coatings during MAO. The surface morphologies of the microarc oxidation coatings and the composite coatings are exhibited in Fig. 2. The MAO coatings prepared in an electrolyte without nanorutile $\mathrm{TiO}_{2}$ particles contained many crater-like micropores and a few microcracks. These pores were discharge channels

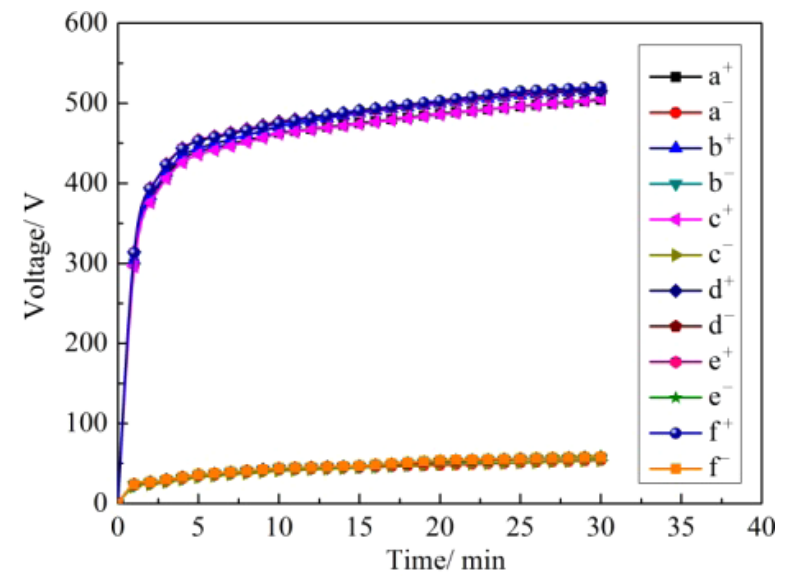

Fig. 1. (Color online) Variation curves of voltage during preparation of microarc oxidation coatings in an electrolyte containing nanorutile $\mathrm{TiO}_{2}$ particles: (a) $0 \mathrm{~g} / \mathrm{L}$, (b) $0.7 \mathrm{~g} / \mathrm{L}$, (c) $1.4 \mathrm{~g} / \mathrm{L}$, (d) $2.1 \mathrm{~g} / \mathrm{L}$, (e) $2.8 \mathrm{~g} / \mathrm{L}$ and (f) $3.5 \mathrm{~g} / \mathrm{L}$.

formed by spark discharge. In the process of MAO, molten "oxide magma" was formed in the discharge channels due to the localized high temperature and high pressure (approximately $2 \times 10^{4} \mathrm{~K}$ and $\left.10^{2} \mathrm{MPa}\right){ }^{31,32}$ The molten "oxide magma" was cooled, solidified and stacked instantaneously to form the MAO coatings. The rapid cooling of the molten "oxide magma," however, also produced thermal stress, which caused the microcracks. Figure 2 presents that the porosity of the composite coatings decreased remarkably as the content of rutile $\mathrm{TiO}_{2}$ particles in the electrolyte changed from $0 \mathrm{~g} / \mathrm{L}$ to $3.5 \mathrm{~g} / \mathrm{L}$ because part of the nanorutile $\mathrm{TiO}_{2}$ particles are captured by the micropores on the composite coatings and the micropores are filled during MAO. As shown in Figs. 2(d)-2(f), the number of microcracks increased remarkably as the content of nanorutile $\mathrm{TiO}_{2}$ particles in the electrolyte changed from $2.1 \mathrm{~g} / \mathrm{L}$ to $3.5 \mathrm{~g} / \mathrm{L}$. More microcracks were produced by the increase and uneven distribution of the thermal stress, which was promoted by some of the nanorutile $\mathrm{TiO}_{2}$ particles filling the micropores on the composite ceramic coatings and other rutile $\mathrm{TiO}_{2}$ particles agglomerating and forming large bulges on the composite coatings.

Figure 3 exhibits the surface roughnesses of the microarc oxidation composite coatings. The surface roughness of the microarc oxidation composite coatings decreased with increasing content of nanorutile $\mathrm{TiO}_{2}$ particles in the electrolyte from $0 \mathrm{~g} / \mathrm{L}$ to $0.7 \mathrm{~g} / \mathrm{L}$. 


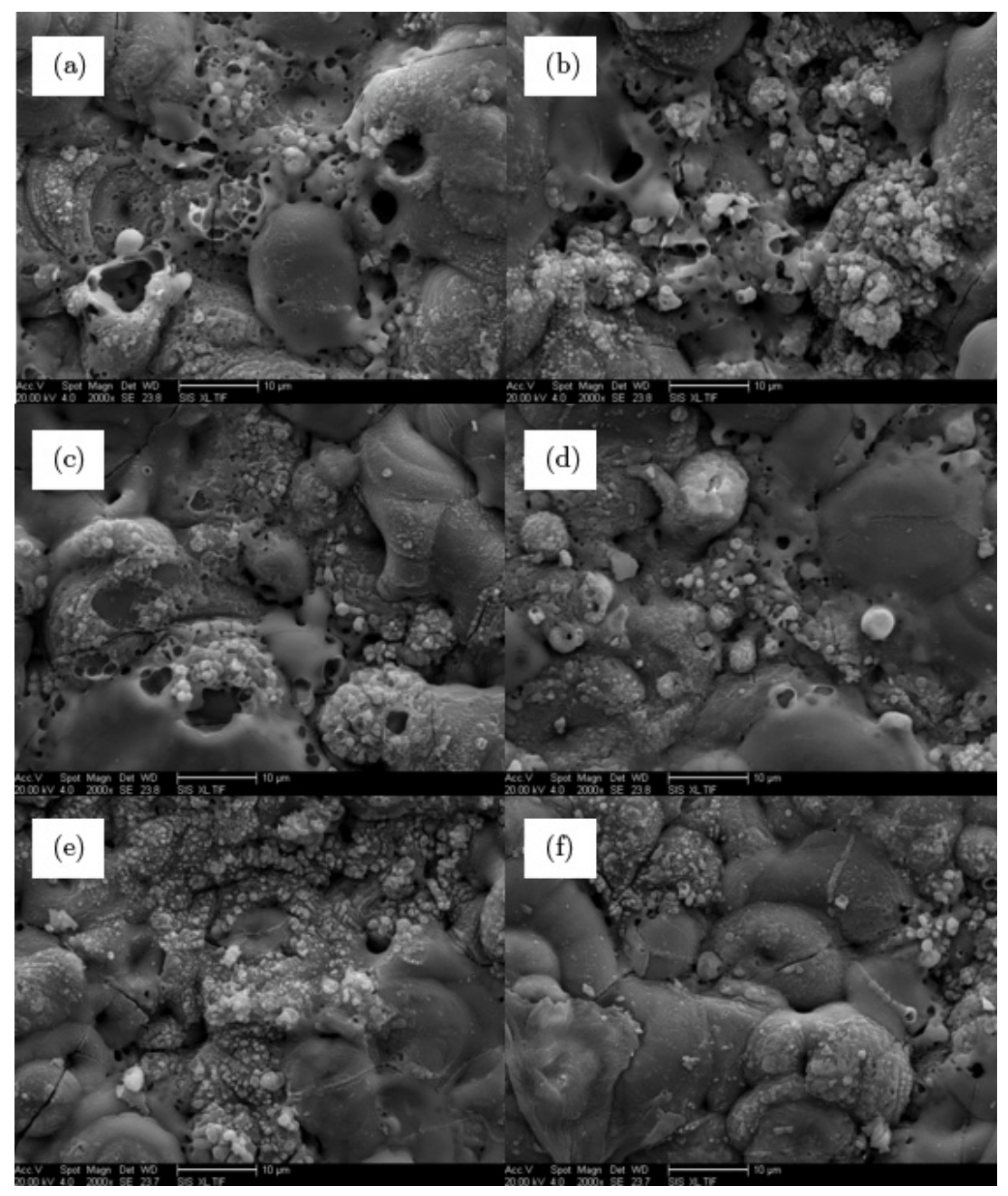

Fig. 2. Surface morphologies of the microarc oxidation composite coatings prepared in an electrolyte containing nanorutile $\mathrm{TiO}_{2}$ particles: (a) $0 \mathrm{~g} / \mathrm{L}$, (b) $0.7 \mathrm{~g} / \mathrm{L}$, (c) $1.4 \mathrm{~g} / \mathrm{L}$, (d) $2.1 \mathrm{~g} / \mathrm{L}$, (e) $2.8 \mathrm{~g} / \mathrm{L}$ and (f) $3.5 \mathrm{~g} / \mathrm{L}$.

The surface roughness of the microarc oxidation composite coatings, however, increased remarkably with increasing content of nanorutile $\mathrm{TiO}_{2}$ particles in the electrolyte from $0.7 \mathrm{~g} / \mathrm{L}$ to $3.5 \mathrm{~g} / \mathrm{L}$. The surface roughness of the microarc oxidation composite coatings prepared in the electrolyte with $0.7 \mathrm{~g} / \mathrm{L}$ nanorutile $\mathrm{TiO}_{2}$ particles was the smallest because the surface pores of microarc oxidation composite ceramic coatings were filled with nanorutile $\mathrm{TiO}_{2}$ particles. However, the surface roughness of the microarc oxidation composite coatings prepared in the electrolyte with $3.5 \mathrm{~g} / \mathrm{L}$ nanorutile $\mathrm{TiO}_{2}$ particles was the largest because the surface pores of composite coatings were filled by only a part of nanorutile $\mathrm{TiO}_{2}$ particles, whereas the other part of nanorutile $\mathrm{TiO}_{2}$ particles agglomerated on the surface of the microarc oxidation composite coatings to form large bulges.

The cross-section morphologies and thicknesses of the MAO coatings prepared in an electrolyte without nanorutile $\mathrm{TiO}_{2}$ particles and the composite coatings prepared in an electrolyte containing nanorutile $\mathrm{TiO}_{2}$ particles are shown in Figs. 4 and 5, respectively. The MAO coatings and the composite coatings exhibited an obvious double layer. The compactness of the inner layer was higher than the compactness of the outer layer. In the composite coatings, with increasing content of nanorutile $\mathrm{TiO}_{2}$ particles in the electrolyte, the thickness of the dense layer increased and the porous layer became thinner. The compactness of the composite coatings was remarkably improved due 


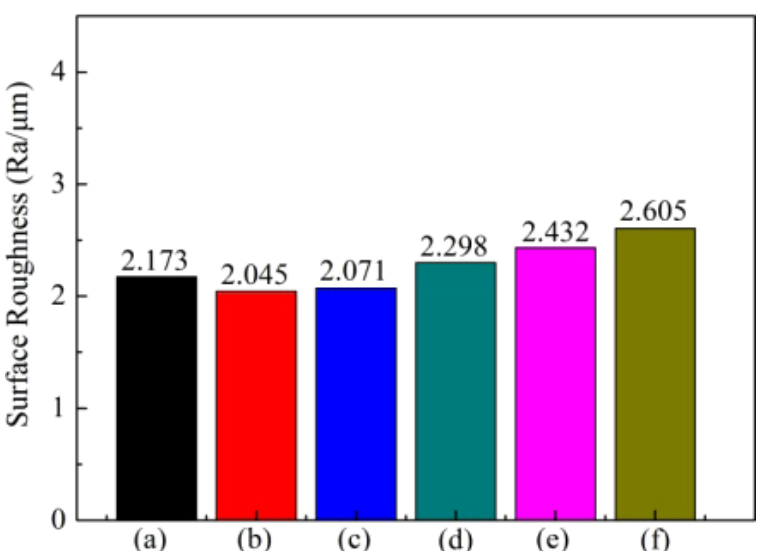

Fig. 3. (Color online) Surface roughness values of the microarc oxidation composite coatings prepared in an electrolyte containing nanorutile $\mathrm{TiO}_{2}$ particles: (a) $0 \mathrm{~g} / \mathrm{L}$, (b) $0.7 \mathrm{~g} / \mathrm{L}$, (c) $1.4 \mathrm{~g} / \mathrm{L}$, (d) $2.1 \mathrm{~g} / \mathrm{L}$, (e) $2.8 \mathrm{~g} / \mathrm{L}$ and (f) $3.5 \mathrm{~g} / \mathrm{L}$. to many micropores on the composite coatings being filled with rutile $\mathrm{TiO}_{2}$ particles.

The cross-section element distributions of the MAO coatings prepared in an electrolyte without nanorutile $\mathrm{TiO}_{2}$ particles and the composite coatings prepared in an electrolyte containing nanorutile $\mathrm{TiO}_{2}$ particles are shown in Fig. 6. Figure 6 shows that $\mathrm{Ti}$ was detected in the dense layer and the porous layer of the composite coatings, inferring that nanorutile $\mathrm{TiO}_{2}$ particles were mixed into the composite coatings.

\subsection{XRD patterns}

As shown in Fig. 7, XRD analysis results revealed that the MAO coatings prepared in an electrolyte without nanorutile $\mathrm{TiO}_{2}$ particles were mainly

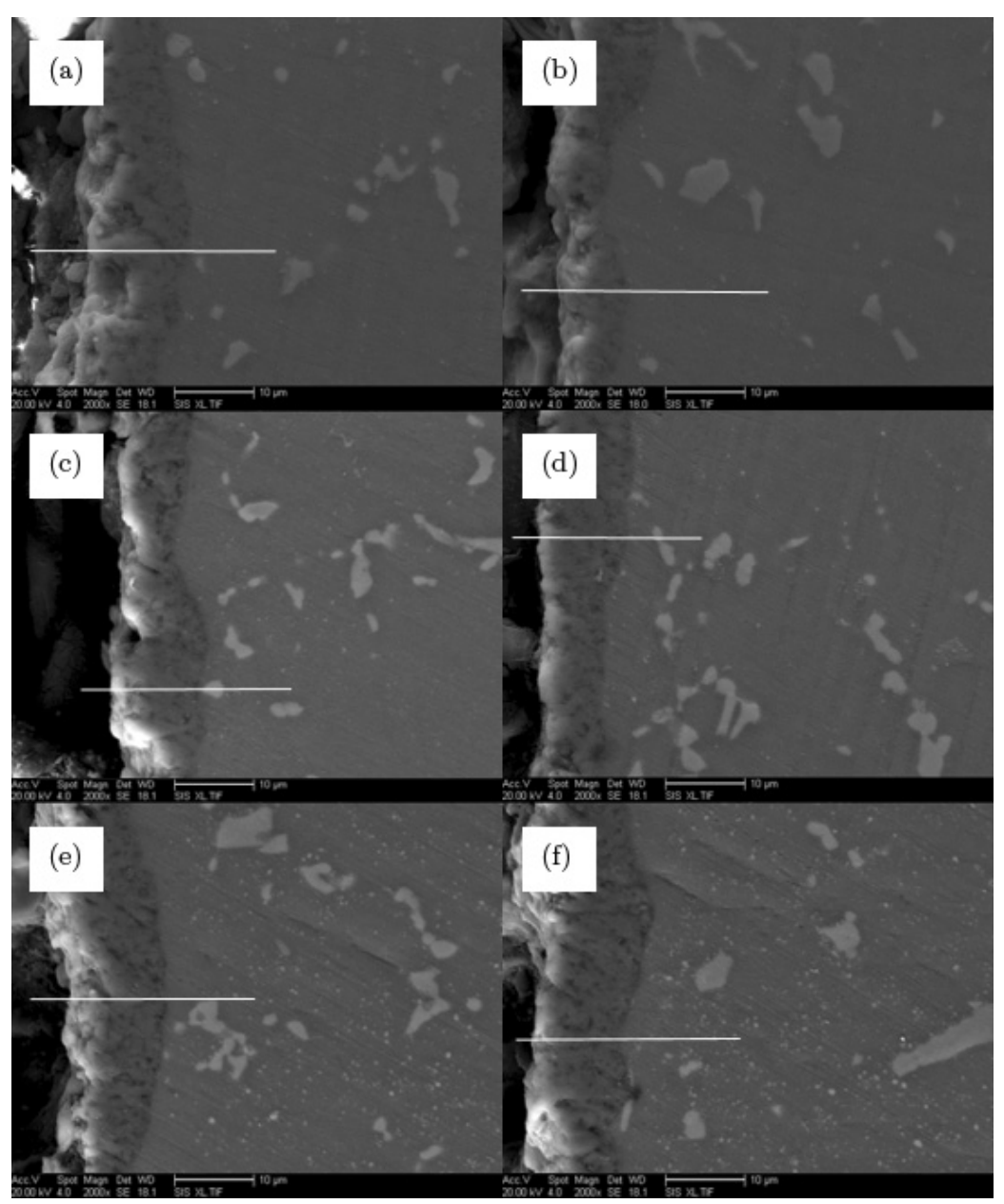

Fig. 4. The cross-section morphologies of the microarc oxidation composite coatings prepared in an electrolyte containing nanorutile $\mathrm{TiO}_{2}$ particles: (a) $0 \mathrm{~g} / \mathrm{L}$, (b) $0.7 \mathrm{~g} / \mathrm{L}$, (c) $1.4 \mathrm{~g} / \mathrm{L}$, (d) $2.1 \mathrm{~g} / \mathrm{L}$, (e) $2.8 \mathrm{~g} / \mathrm{L}$ and (f) $3.5 \mathrm{~g} / \mathrm{L}$. 


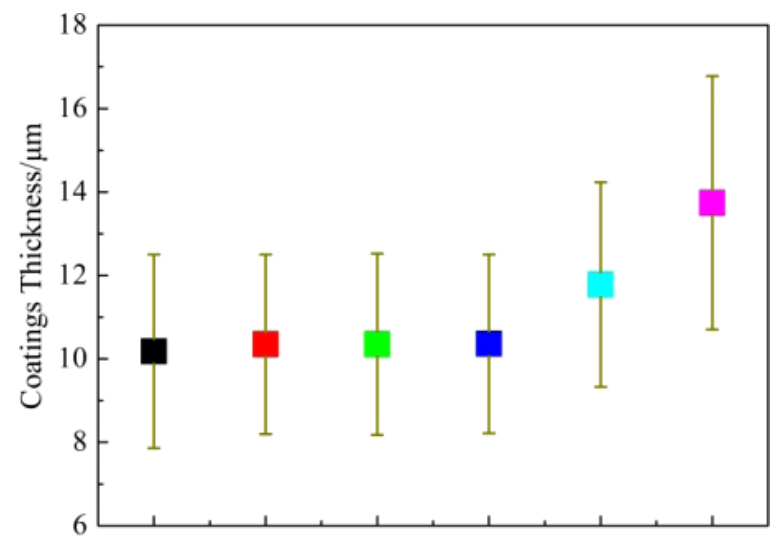

$\begin{array}{llllll}(\mathrm{a}) & \text { (b) } & \text { (c) } & \text { (d) } & \text { (e) } & \text { (f) }\end{array}$

Fig. 5. (Color online) The thicknesses of the microarc oxidation composite coatings prepared in an electrolyte containing nanorutile $\mathrm{TiO}_{2}$ particles: (a) $0 \mathrm{~g} / \mathrm{L}$, (b) $0.7 \mathrm{~g} / \mathrm{L}$, (c) $1.4 \mathrm{~g} / \mathrm{L}$, (d) $2.1 \mathrm{~g} / \mathrm{L}$, (e) $2.8 \mathrm{~g} / \mathrm{L}$ and (f) $3.5 \mathrm{~g} / \mathrm{L}$.

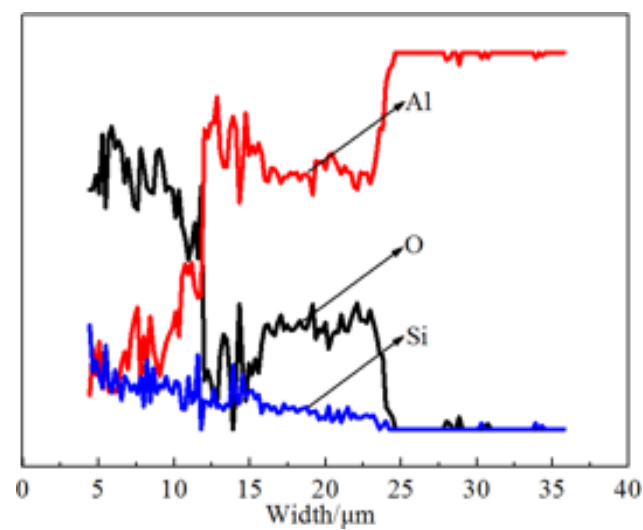

(a)

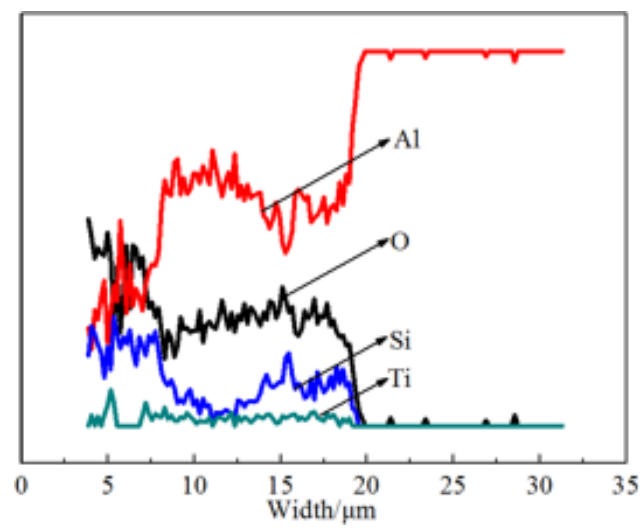

(c) composed of $\gamma-\mathrm{Al}_{2} \mathrm{O}_{3}, \alpha-\mathrm{Al}_{2} \mathrm{O}_{3}$ and mullite. The composite coatings prepared in an electrolyte with nanorutile $\mathrm{TiO}_{2}$ particles contained $\gamma-\mathrm{Al}_{2} \mathrm{O}_{3}$, $\alpha-\mathrm{Al}_{2} \mathrm{O}_{3}$, mullite and rutile $\mathrm{TiO}_{2}$. Rutile $\mathrm{TiO}_{2}$ was detected in the microarc oxidation composite ceramic coatings, which indicated that rutile $\mathrm{TiO}_{2}$ particles directly diffused and adsorbed on to the composite coatings. Moreover, with increasing nanorutile $\mathrm{TiO}_{2}$ particles in the electrolyte, the rutile $\mathrm{TiO}_{2}$ in the composite coatings increased significantly.

\subsection{Adhesive strength of coatings}

The supplementary data graphics of the scratch are shown in Fig. 8. The critical loads at which the acoustic emission and friction coefficient increased rapidly are indicated on the graphs. Table 2 exhibits

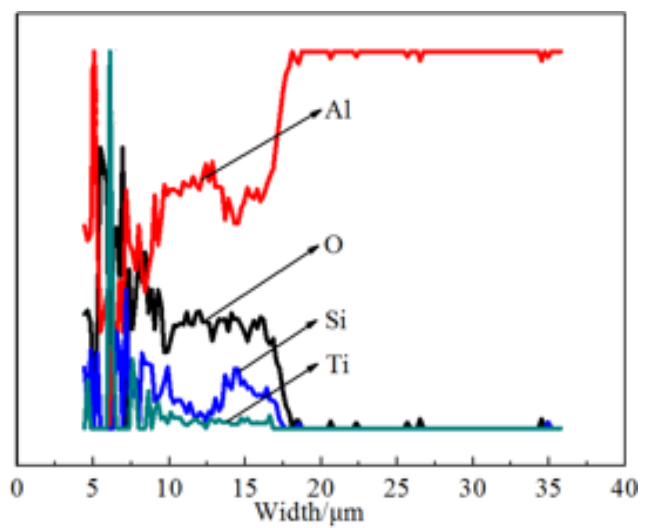

(b)

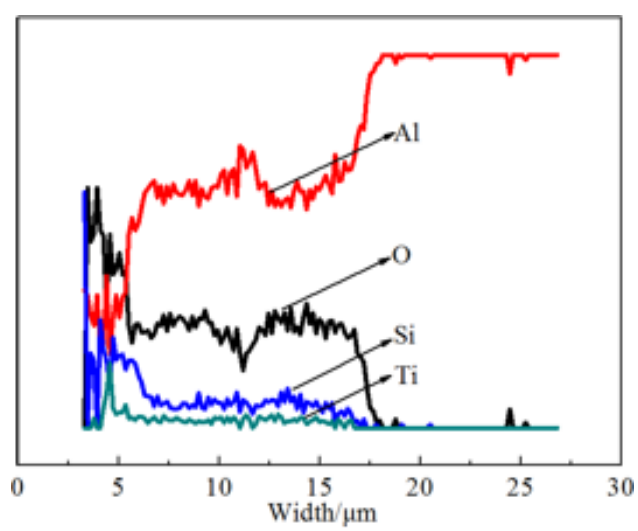

(d)

Fig. 6. (Color online) The cross-section element distributions of the microarc oxidation composite coatings prepared in an electrolyte containing nanorutile $\mathrm{TiO}_{2}$ particles: (a) $0 \mathrm{~g} / \mathrm{L}$, (b) $0.7 \mathrm{~g} / \mathrm{L}$, (c) $1.4 \mathrm{~g} / \mathrm{L}$, (d) $2.1 \mathrm{~g} / \mathrm{L}$, (e) $2.8 \mathrm{~g} / \mathrm{L}$ and (f) $3.5 \mathrm{~g} / \mathrm{L}$. 


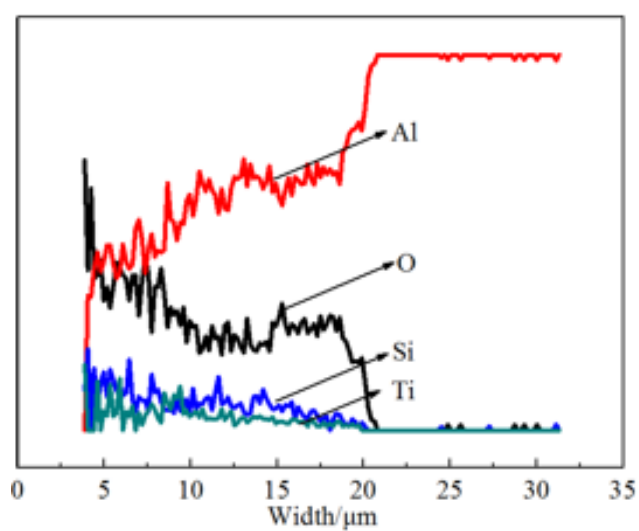

(e)

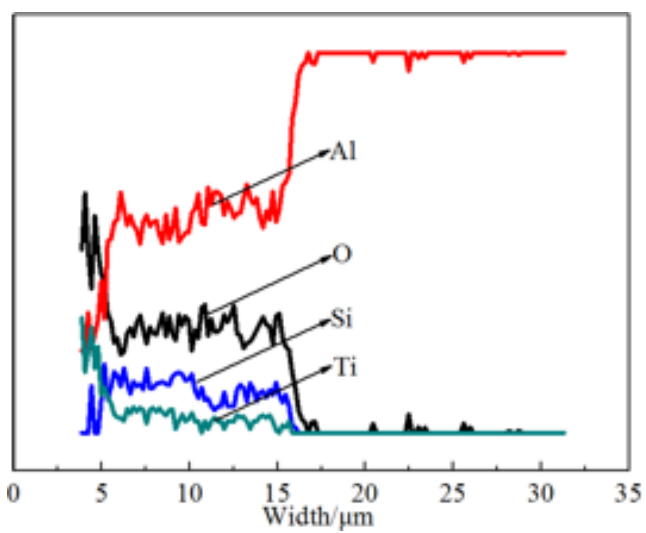

(f)

Fig. 6. (Continued)

the critical load values of the microarc oxidation composite coatings. It can be found that with increasing content of nanorutile $\mathrm{TiO}_{2}$ particles in the electrolyte, the corresponding critical load values on the composite coatings decreased significantly because more nanorutile $\mathrm{TiO}_{2}$ particles were mixed into the composite coatings, which decreased the adhesive strength between the coatings and substrate.

\subsection{Microhardness and wear resistance of coatings}

Figure 9 shows the hardness values of the composite coatings prepared in an electrolyte with different

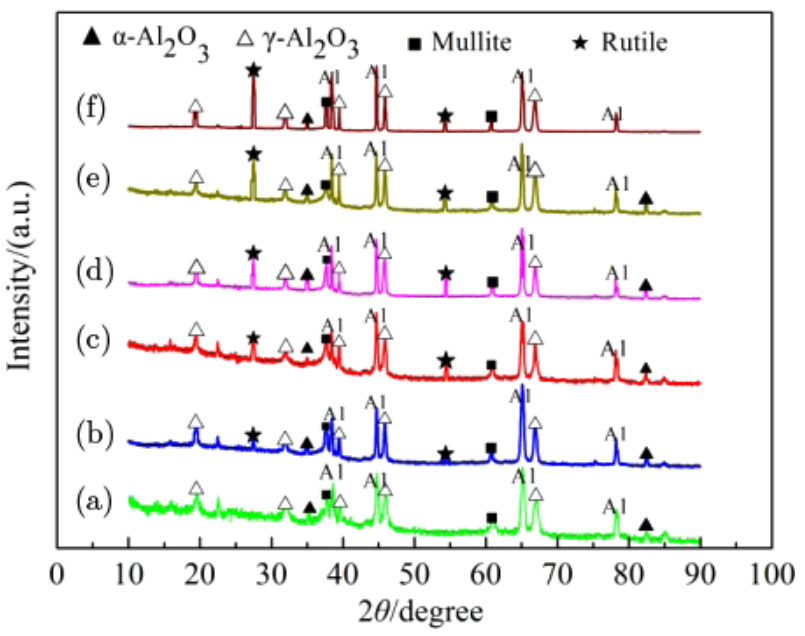

Fig. 7. (Color online) XRD patterns of the microarc oxidation composite coatings: (a) $0 \mathrm{~g} / \mathrm{L}$, (b) $0.7 \mathrm{~g} / \mathrm{L}$, (c) $1.4 \mathrm{~g} / \mathrm{L}$, (d) $2.1 \mathrm{~g} / \mathrm{L}$, (e) $2.8 \mathrm{~g} / \mathrm{L}$ and (f) $3.5 \mathrm{~g} / \mathrm{L}$. concentrations of nanorutile $\mathrm{TiO}_{2}$ particles. The hardness of the composite coatings increased significantly as the concentration of rutile $\mathrm{TiO}_{2}$ particles in the electrolyte increased from $0 \mathrm{~g} / \mathrm{L}$ to $2.1 \mathrm{~g} / \mathrm{L}$ because the surface pores of the composite coating were filled by rutile $\mathrm{TiO}_{2}$ particles and the density of the ceramic coatings was improved. However, the hardness of the microarc oxidation composite coatings decreased rapidly as the rutile $\mathrm{TiO}_{2}$ particles in the electrolyte increased from $2.1 \mathrm{~g} / \mathrm{L}$ to $3.5 \mathrm{~g} / \mathrm{L}$ because more rutile $\mathrm{TiO}_{2}$ particles were mixed into the composite coatings and the hardness of $\mathrm{Al}_{2} \mathrm{O}_{3}$ is higher than the hardness of rutile $\mathrm{TiO}_{2}$.

Figure 10 shows the friction coefficients of the wear tracks for the microarc oxidation composite coatings prepared in an electrolyte containing nanorutile $\mathrm{TiO}_{2}$ particles against WC balls at room temperature during wear testing. Wave peaks existed on the microarc oxidation composite coatings and WC balls, and the friction coefficient increased rapidly in the initial stages of the friction test. After $1000 \mathrm{~s}$, the wave peaks were smoothed flat and the friction coefficient became stable. Moreover, compared to the microarc oxidation coatings, the microarc oxidation composite coatings exhibited a lower friction coefficient, and the fluctuation range of the friction coefficient of the microarc oxidation coatings was narrower.

Figure 11 exhibits the morphologies of the wear tracks for the microarc oxidation composite coatings prepared in an electrolyte containing nanorutile $\mathrm{TiO}_{2}$ particles against WC balls at room 


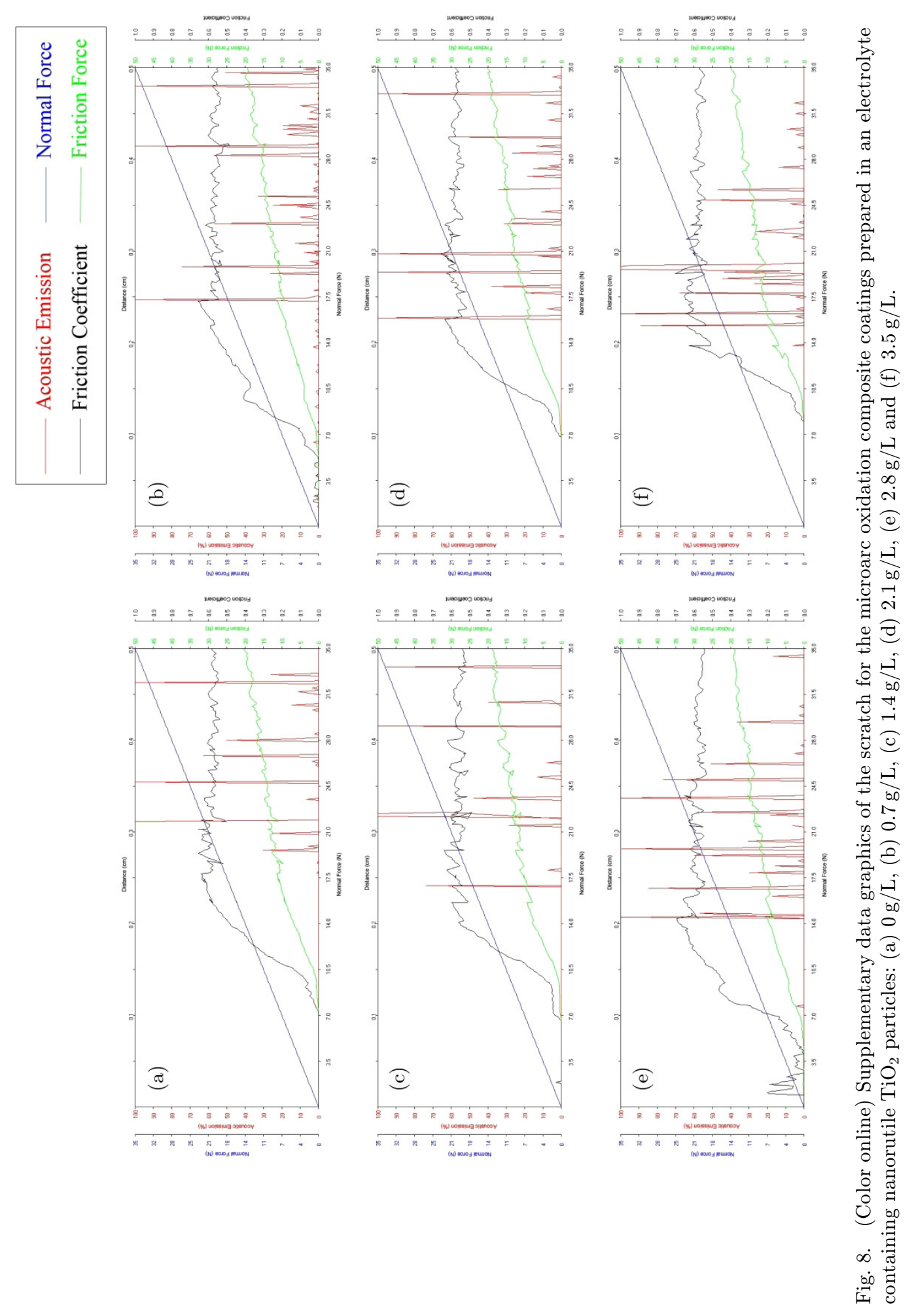


Table 2. Critical load values of the MAO coatings.

\begin{tabular}{lc}
\hline Coatings & $L c(\mathrm{~N})$ \\
\hline A [Fig. 8(a)] & 17.9 \\
B [Fig. 8(b)] & 17.3 \\
C [Fig. 8(c)] & 16.9 \\
D [Fig. 8(d)] & 16.0 \\
E [Fig. 8(e)] & 14.5 \\
F [Fig. 8(f)] & 13.8 \\
\hline
\end{tabular}

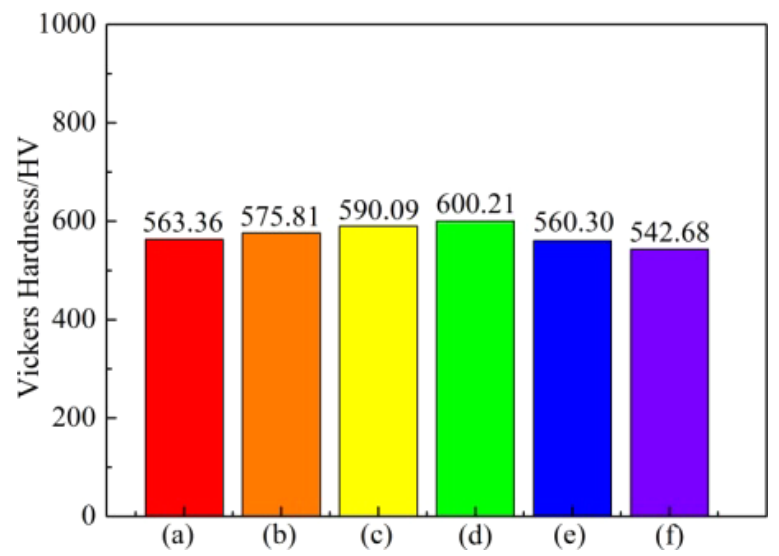

Fig. 9. (Color online) The hardness values of the microarc oxidation composite coatings prepared in an electrolyte containing nanorutile $\mathrm{TiO}_{2}$ particles: (a) $0 \mathrm{~g} / \mathrm{L}$, (b) $0.7 \mathrm{~g} / \mathrm{L}$, (c) $1.4 \mathrm{~g} / \mathrm{L}$, (d) $2.1 \mathrm{~g} / \mathrm{L}$, (e) $2.8 \mathrm{~g} / \mathrm{L}$ and (f) $3.5 \mathrm{~g} / \mathrm{L}$.

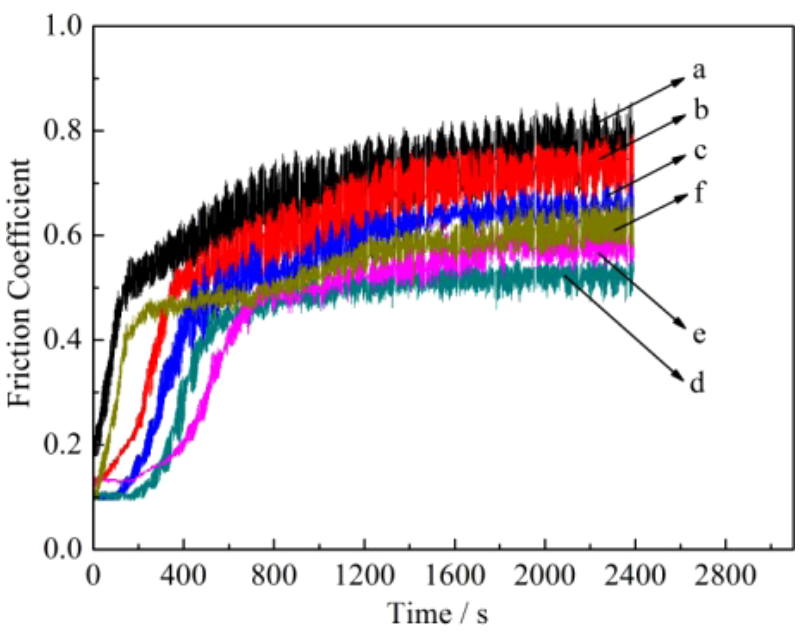

Fig. 10. (Color online) Friction coefficient curves during wear testing: (a) $0 \mathrm{~g} / \mathrm{L}$, (b) $0.7 \mathrm{~g} / \mathrm{L}$, (c) $1.4 \mathrm{~g} / \mathrm{L}$, (d) $2.1 \mathrm{~g} / \mathrm{L}$, (e) $2.8 \mathrm{~g} / \mathrm{L}$ and (f) $3.5 \mathrm{~g} / \mathrm{L}$. temperature after wear testing. The morphologies of the wear tracks for the microarc oxidation coatings exhibited serious furrows. The morphologies of the wear tracks for the microarc oxidation composite coatings prepared in the electrolyte with $3.5 \mathrm{~g} / \mathrm{L}$ rutile $\mathrm{TiO}_{2}$ particles showed a wide range of exfoliation. The morphologies of the wear tracks for the microarc oxidation composite coatings prepared in the electrolyte with $2.1 \mathrm{~g} / \mathrm{L}$ rutile $\mathrm{TiO}_{2}$ particles showed mild furrows and exfoliation, which showed that the main wear mechanism was abrasive wear and fatigue wear.

Table 3 shows the wear rates of the wear tracks for the microarc oxidation composite coatings prepared in an electrolyte containing nanorutile $\mathrm{TiO}_{2}$ particles against WC balls at room temperature after wear testing. It can be found that the wear rates of the microarc oxidation composite coatings decreased remarkably because rutile $\mathrm{TiO}_{2}$ particles were added to the electrolyte. In the electrolyte, when the content of nanorutile $\mathrm{TiO}_{2}$ particles was more than $2.1 \mathrm{~g} / \mathrm{L}$, however, the wear rates of the microarc oxidation composite coatings increased. The wear rate of the microarc oxidation composite coatings formed in the electrolyte with $2.1 \mathrm{~g} / \mathrm{L}$ rutile $\mathrm{TiO}_{2}$ particles was the lowest, and the wear rate was only $31.5 \%$ that of the MAO coatings.

It is well known that the friction coefficient of ceramic materials is high, and the high porosity of the microarc oxidation coating prompted an unstable friction coefficient. During wear testing, the microbulges on the WC balls easily penetrated into the surface of MAO coatings, which caused serious abrasive wear of the MAO coatings. In contrast, the micropores on the surface of the composite coatings were filled with rutile $\mathrm{TiO}_{2}$ particles. The density of the composite coatings was higher than the density of the MAO coatings, causing a stable friction coefficient. Meanwhile, during wear testing, because the rutile $\mathrm{TiO}_{2}$ particles in the micropores could be used as a solid lubricant, the friction coefficient of the composite coatings was decreased remarkably. The wear rates of the composite coatings with high density and microlubricating performance were reduced significantly. However, when the concentration of rutile $\mathrm{TiO}_{2}$ particles in the electrolyte exceeded a certain value, many microcracks appeared on the composite coatings [Figs. 2(e) and 2(f)]. During wear testing, these microcracks easily expanded and 


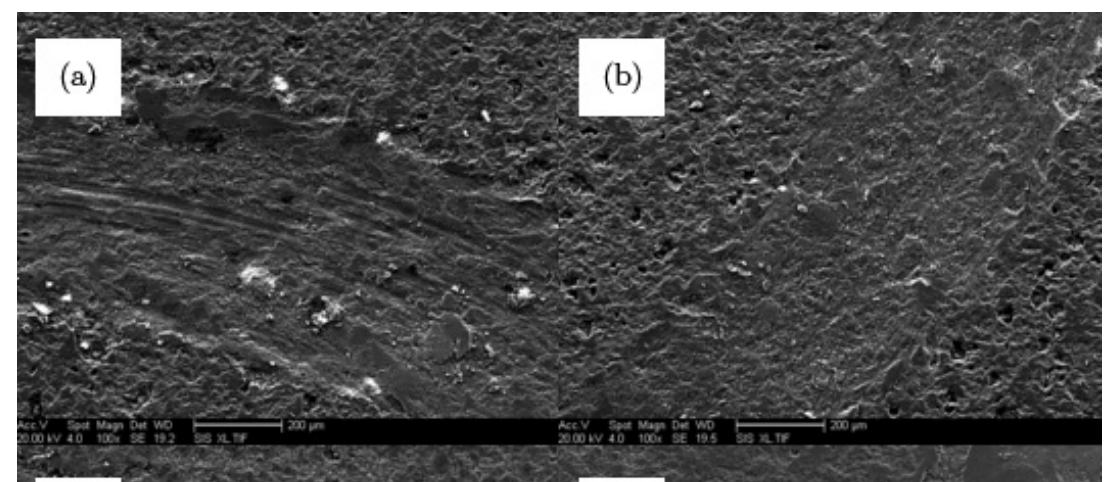

(c)

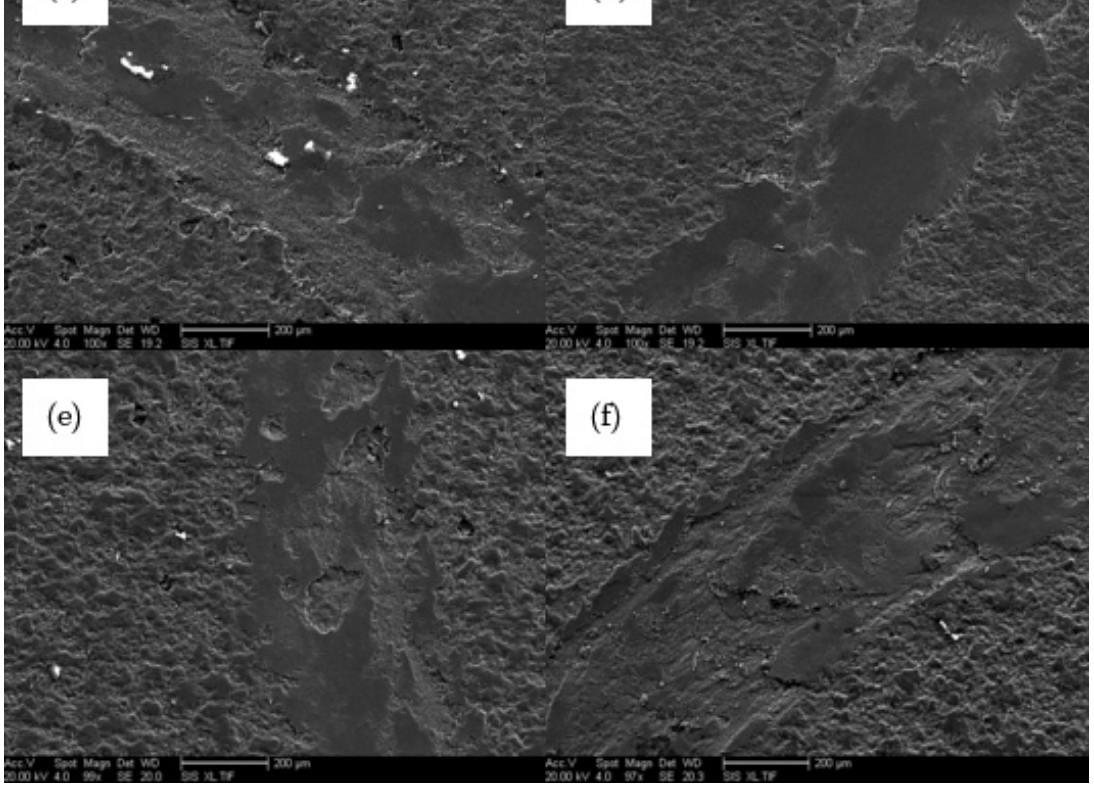

Fig. 11. The morphologies of the wear tracks for the microarc oxidation composite coatings produced in an electrolyte containing nanorutile $\mathrm{TiO}_{2}$ particles: (a) $0 \mathrm{~g} / \mathrm{L}$, (b) $0.7 \mathrm{~g} / \mathrm{L}$, (c) $1.4 \mathrm{~g} / \mathrm{L}$, (d) $2.1 \mathrm{~g} / \mathrm{L}$, (e) $2.8 \mathrm{~g} / \mathrm{L}$ and (f) $3.5 \mathrm{~g} / \mathrm{L}$.

formed exfoliation [Figs. 11(e) and 11(f)]. Exfoliation could play a microcutting role and could plough the friction surface, increasing the wear rates of the composite coatings.

\subsection{Wear mechanism of coatings}

Based on the friction behavior of the microarc oxidation composite coatings, the wear mechanism of the composite coating is as follows.

Table 3. Wear rates of the coatings.

\begin{tabular}{lcccc}
\hline Coatings & Wear time $(\mathrm{s})$ & Wear track width $(\mu \mathrm{m})$ & Wear track depth $(\mu \mathrm{m})$ & Wear rate $\left(\mathrm{mm}^{3} \cdot \mathrm{N}^{-1} \cdot \mathrm{m}^{-1}\right)$ \\
\hline A [Fig. 11(a)] & 2400 & 615.38 & 4.67 & $0.038 \times 10^{-4}$ \\
B [Fig. 11(b)] & 2400 & 538.46 & 3.34 & $0.024 \times 10^{-4}$ \\
C [Fig. 11(c)] & 2400 & 461.54 & 2.67 & $0.016 \times 10^{-4}$ \\
D [Fig. 11(d)] & 2400 & 415.38 & 2.18 & $0.012 \times 10^{-4}$ \\
E [Fig. 11(e)] & 2400 & 446.15 & 2.58 & $0.015 \times 10^{-4}$ \\
F [Fig. 11(f)] & 2400 & 492.31 & 3.05 & $0.021 \times 10^{-4}$ \\
\hline
\end{tabular}


(a) The micropores and microcracks on the composite ceramic coatings were filled with rutile $\mathrm{TiO}_{2}$ particles in the process of $\mathrm{MAO}$, and the density of the composite coatings was improved significantly, which made the penetration of the microbulges on the WC balls into the surface of composite coatings more difficult and reduced the wear depth of the composite coatings. Meanwhile, during wear testing, the friction coefficient of the composite coatings was decreased remarkably because the rutile $\mathrm{TiO}_{2}$ particles in the micropores could be used as a solid lubricant.

(b) When the content of the rutile $\mathrm{TiO}_{2}$ particles in the electrolyte exceeded a certain value, many microcracks were found on the surface of the microarc oxidation composite coatings. During wear testing, these microcracks easily expanded and formed exfoliation. Some of the exfoliation was squeezed into the composite coatings under the action of the normal loads and can seriously plough the friction surface, which increased the wear rates of the composite coatings.

(c) When the contents of the rutile $\mathrm{TiO}_{2}$ particles in the electrolyte exceeded a certain value, many rutile $\mathrm{TiO}_{2}$ particles easily agglomerated and formed big bumps on the surface of the composite coatings. During wear testing, these large bulges can easily fall off. Some of the exfoliation was squeezed into the composite coatings due to the action of the normal loads and can seriously plough the friction surface, which increased the wear volume of the microarc oxidation composite coatings.

\section{Conclusions}

A 2024 aluminum alloy was treated by MAO in a silicate system electrolyte with different concentrations of nanorutile $\mathrm{TiO}_{2}$ particles, and microarc oxidation composite coatings were prepared. The microarc oxidation coatings formed in the electrolyte without rutile $\mathrm{TiO}_{2}$ particles contained many craterlike micropores of various sizes. These holes on the surface of microarc oxidation composite ceramic coatings decreased significantly.

The microarc oxidation composite coatings mainly consisted of $\gamma-\mathrm{Al}_{2} \mathrm{O}_{3}, \alpha-\mathrm{Al}_{2} \mathrm{O}_{3}$, mullite and rutile $\mathrm{TiO}_{2}$. With increasing nanorutile $\mathrm{TiO}_{2}$ particles in the electrolyte, rutile $\mathrm{TiO}_{2}$ in the composite coatings increased significantly.

Compared to the microarc oxidation coatings, the microarc oxidation composite coatings produced in the electrolyte containing $2.1 \mathrm{~g} / \mathrm{L}$ rutile $\mathrm{TiO}_{2}$ particles exhibited the lowest wear rate, which was only $31.5 \%$ that of the microarc oxidation coatings, and the microarc oxidation composite coatings exhibited better wear resistance.

\section{Acknowledgments}

The authors gratefully acknowledge the Micro/Nano Technology Research Center, Harbin Institute of Technology for the device support.

\section{References}

1. K. C. Tekin, U. Malayoglu and S. Shrestha, Surf. Eng. 32 (2016) 435.

2. Z. Shao, B. Kong, Y. Zhao and Z. Cai, Surf. Eng. 30 (2014) 893.

3. P. Wang, J. P. Li, Y. C. Guo, Z. Yang and J. L. Wang, Surf. Eng. 32 (2016) 428.

4. B. Rajasekaran, S. G. S. Raman, L. R. Krishna, S. V. Joshi and G. Sundarajan, Surf. Coat. Technol. 202 (2008) 1462.

5. C. C. Tseng, J. L. Lee, T. H. Kuo, S. N. Kuo and K. H. Tseng, Surf. Coat. Technol. 206 (2012) 3437.

6. A. Polat, M. Makaraci and M. Usta, J. Alloys Compd. 504 (2010) 519.

7. C. J. Hu and M. H. Hsieh, Surf. Coat. Technol. 258 (2014) 275.

8. K. R. Shin, Y. S. Kim, J. H. Jeong, Y. G. Ko and D. H. Shin, Surf. Eng. 32 (2016) 418.

9. L. R. Krishna, A. S. Purnima and G. Sundararajan, Wear 261 (2006) 1095.

10. Z. J. Wang, L. Wu, Y. L. Qi, W. Cai and Z. H. Jiang, Surf. Coat. Technol. 204 (2010) 3315.

11. T. B. Wei, F. Y. Yan and J. Tian, J. Alloys Compd. 389 (2005) 169.

12. S. A. Yavari, B. S. Necula, L. E. Fratila-Apachitei, J. Duszczyk and I. Apachitei, Surf. Eng. 32 (2016) 411.

13. M. Wang, S. Y. Guo, Y. L. Wang, H. Wang, Y. J. Yao and T. X. Min, Surf. Eng. 32 (2016) 423.

14. W. Yang, J. L. Wang, D. P. Xu, P. L. Ke and J. P. Li, Surf. Eng. 32 (2016) 601.

15. M. A. Chen, Y. C. Ou, C. Y. Yu, C. Xiao and S. Y. Liu, Surf. Eng. 32 (2016) 38.

16. Y. L. Cheng, Z. G. Xue, Q. Wang, X. Q. Wu, E. Matykina, P. Skeldon and G. E. Thompson, Electrochim. Acta 107 (2013) 358. 
17. J. Martin, P. Leone, A. Nomine, D. V. Renaux, G. Henrion and T. Belmonte, Surf. Coat. Technol. 269 (2015) 36.

18. W. B. Xue, Z. W. Deng, R. Y. Chen and T. H. Zhang, Thin Solid Films 372 (2000) 114.

19. H. Khanmohammadi, S. R. Allahkaram, N. Towhidi and A. M. Rashidfarokhi, Surf. Eng. 32 (2016) 448.

20. J. M. Li, H. Cai and B. L. Jiang, Surf. Coat. Technol. 201 (2007) 8702.

21. Y. J. Guan, Y. Xia and F. T. Xu, Surf. Coat. Technol. 202 (2008) 4204.

22. M. Mu, X. J. Zhou, Q. Xiao, J. Liang and X. D. Huo, Appl. Surf. Sci. 258 (2012) 8570.

23. M. Mu, J. Liang, X. J. Zhou and Q. Xiao, Surf. Coat. Technol. 214 (2013) 124.

24. H. Li, Y. Z. Sun and J. Zhang, Appl. Surf. Sci. 342 (2015) 183.
25. A. Mandelli, M. Bestetti, A. D. Forno, N. Lecis, S. P. Trasatti and M. Trueba, Surf. Coat. Technol. 205 (2011) 4459.

26. K. J. Ma, M. M. S. A. Bosta and W. T. Wu, Surf. Coat. Technol. 259 (2014) 318.

27. Y. Bai, K. A. Kim, S. Park, S. J. Lee, T. S. Bae and M. H. Lee, Mater. Sci. Eng. B 176 (2011) 1213.

28. Y. Q. Wang, X. D. Jiang and C. X. Pan, J. Alloys Compd. 538 (2012) 16.

29. S. Y. Wang, N. C. Si, Y. P. Xia and L. Liu, Trans. Nonferr. Met. Soc. China 25 (2015) 1926.

30. Y. S. Kim, K. R. Shin, G. W. Kim, Y. G. Ko and D. H. Shin, Surf. Eng. 32 (2016) 443.

31. A. L. Yerokhin, L. O. Snizhko, N. L. Gurevina, A. Leyland, A. Pilkington and A. Matthews, J. Phys. D, Appl. Phys. 36 (2003) 2110.

32. C. S. Dunleavy, I. O. Golosnoy, J. A. Curran and T. W. Clyne, Surf. Coat. Technol. 203 (2009) 3410. 